Article

\title{
Optimization Design and Experimental Testing of a Laser Receiver for Use in a Laser Levelling Control System
}

\author{
Ying Zang ${ }^{1,2}$, Shibo Meng ${ }^{1}$, Lian Hu ${ }^{1,2, * \mathbb{D}}$, Xiwen Luo ${ }^{1,2}$, Runmao Zhao ${ }^{1} \mathbb{D}$, Pan Du ${ }^{1}$, \\ Jinkang Jiao ${ }^{1}$, Hao Huang ${ }^{1}$ and Gaolong Chen ${ }^{1}$ \\ 1 Key Laboratory of Key Technology for South Agricultural Machine and Equipment, Ministry of Education, \\ South China Agricultural University, Guangzhou 510642, China; yingzang@scau.edu.cn (Y.Z.); \\ mshibo@163.com (S.M.); xwluo@scau.edu.cn (X.L.); zhrm_2007@163.com (R.Z.); dupan2018@126.com (P.D.); \\ jiaojk320@163.com (J.J.); hhcaden163@163.com (H.H.); dbalong@163.com (G.C.) \\ 2 Guangdong Laboratory for Lingnan Modern Agriculture, Guangzhou 510642, China \\ * Correspondence: lianhu@scau.edu.cn; Tel.: +86-020-38676975
}

Received: 6 February 2020; Accepted: 16 March 2020; Published: 24 March 2020

\begin{abstract}
The elevation detection accuracy of the laser receiver in the laser levelling control system directly affects land-levelling operations. To effectively improve the effect of levelling operations and meet the requirements for the accuracy of elevation detection in different industries, this study optimization designed a multilevel adjustable laser receiver. First, we examined the laser signal detection technology and processing circuit, designed the photoelectric conversion array for the detection of the rotating laser, and converted it into a photocurrent signal. We also designed the filter, amplifier, and shaping and stretching circuits for analogue-to-digital conversion of the photocurrent signal. The digital signal was calculated based on the deviation of the elevation by using a microprocessor and was output by a controller area network (CAN) bus. The laser beam spot diameter transmission and diffusion were then studied, and with the detectable spot diameters were compared and analyzed. Accordingly, an algorithm was proposed to calculate the deviation of laser receiver elevation. The resolution of the elevation deviation was set to $\pm 3 \mathrm{~mm}$; however, this value could be adjusted to $\pm 6 \mathrm{~mm}, \pm 9 \mathrm{~mm}, \pm 12 \mathrm{~mm}$, and $\pm 15 \mathrm{~mm}$, according to the requirements. Finally, the laser receiver was tested and analyzed, and the test results of the elevation detection accuracy showed that when the laser receiver was within a radius of $90 \mathrm{~m}$, the elevation detection accuracy was within the $\pm 3 \mathrm{~mm}$ range. The outcomes of the farmland-levelling test showed that the standard deviation $S_{d}$ of the field surface decreased from $9.54 \mathrm{~cm}$ before levelling to $2.42 \mathrm{~cm}$ after levelling, and the percentage of sampling points associated with absolute errors of $\leq 3 \mathrm{~cm}$ was $84.06 \%$. These outcomes meet the requirements of high-standard farmland construction. The test results of concrete levelling showed that within a radius of $30 \mathrm{~m}$, the standard deviation $S_{d}$ of the elevation adjustment of the left laser receiver was $1.389 \mathrm{~mm}$, and the standard deviation $S_{d}$ of the elevation adjustment of the right laser receiver was $1.316 \mathrm{~mm}$. Furthermore, the percentage of the sampling points associated with absolute elevation adjustment errors of $\leq 3 \mathrm{~mm}$ in the cases of the two laser receivers was $100 \%$ after levelling, whereas the standard deviation $S_{d}$ of the sand bed surface was $0.881 \mathrm{~mm}$. Additionally, the percentage of the sampling points associated with absolute errors of $\leq 3 \mathrm{~mm}$ was $100 \%$. This met the construction standards of the concrete industry.
\end{abstract}

Keywords: laser; laser levelling; laser receiver; photoelectric conversion; signal modulation 


\section{Introduction}

In the 1980s, laser-levelling technology was extensively used in the United States, the former Soviet Union, Germany, and Japan [1]. Laser land-levelling technology can effectively improve the levelling of farmlands, ensure that the distribution of irrigation water is more homogeneous, increase the irrigation efficiency by $10 \%-15 \%$, and save irrigation water by more than $10 \%$. Moreover, it can ensure that the fertilizer is evenly distributed on the roots of the crops, can effectively improve the utilization rate of the fertilizer, reduce the trench area in the field, and increase the cultivated land area by $3 \%-5 \%$. It can also improve the growth environment of the crops, and increase the survival rate and crop yield by more than $20 \%$. Furthermore, it can improve the efficiency of agricultural mechanization and lay the foundation for precise seeding and fertilization [2-14]. The laser level control system is mainly composed of a laser transmitter, laser receiver, controller, hydraulic system, and a scraper. A laser receiver installed on the scraper's mast is used to detect the deviation of the actual elevation of the rotating laser from the expected elevation, and the elevation deviation information is then used to control the hydraulic system to drive the scraper to achieve automatic lifting, thereby achieving accurate farmland levelling [15]. Owing to uneven farmland surfaces [16], some graders are designed with inclination detection and automatic levelling control functions to further improve the levelling of the farmland [17-19].

The laser receiver is an important part of the laser levelling control system, and a variety of laser receivers have been researched and developed. Liu et al. [20] used a red plexiglass to filter background light bands, and then used an interference filter for the second filtering stage, to reduce the interference of natural light on silicon photovoltaic cells. Xie et al. [21] designed an electrical signal amplification circuit for silicon photocells, with the use of integrated operational amplifiers. The laser receiver had a resolution of $\pm 11 \mathrm{~mm}$ and a working range of $150 \mathrm{~m}$. Ke et al. [22] studied the photoelectric conversion characteristics of silicon photovoltaic cells, and optimized the parameters of the photoelectric conversion circuit and amplifier circuit. Based on correlation tests, the factors that affected the amplitude of the photoelectric conversion signal of the laser receiver were analyzed, such as the receiving distance, solar irradiance noise, vibration noise, and effective laser signal amplitude frequency. Accordingly, the laser receiver had a resolution of $\pm 11 \mathrm{~mm}$ and a working range of $250 \mathrm{~m}$. The American Trimble company developed the LS908 laser receiver, and it selected a silicon photocell as the photodetector (photosensitive surface size of $5 \mathrm{~mm} \times 20 \mathrm{~mm}$ ). They also designed an efficient operational amplifier circuit and signal processing circuit, with an elevation detection accuracy of $\pm 10 \mathrm{~mm}$ [23]. With the development of laser levelling technology, the requirements for precision have increased, and many companies have developed high-precision laser receivers. One example is the LR40 laser receiver that was developed by Trimble in the United States; it selected a small silicon photocell as the photodetector (photosensitive surface size of $3 \mathrm{~mm} \times 5 \mathrm{~mm}$ ) and the operational amplifier circuit and the signal processing circuit were optimized, of which the elevation detection accuracy could be set to $\pm 3 \mathrm{~mm}, \pm 6 \mathrm{~mm}, \pm 9 \mathrm{~mm}$ [23]. By contrast, the MLS700 laser receiver developed by Leica in Switzerland, and the LS-B110 laser receiver developed by Topcon in the United States, selected photodiode as the photodetector (photosensitive surface size of $3 \mathrm{~mm} \times 5 \mathrm{~mm}$ ) and designed a fast and stable signal modulation circuit, with elevation detection accuracies of $\pm 3 \mathrm{~mm}[24,25]$. In addition, the LR-8 laser receiver developed by BOSCH in Germany selected a CCD image sensor as the photodetector (photosensitive surface size of $2.5 \mathrm{~mm} \times 34 \mathrm{~mm}$ ) and has an elevation detection accuracy of $\pm 3 \mathrm{~mm}$ [26]. All the aforementioned laser receivers use photocells and photodiodes as photodetectors, and can achieve multilevel adjustable elevation detection accuracy, with a maximum value of $\pm 3 \mathrm{~mm}$. However, the aforementioned laser receivers did not explore the diffusion characteristics of different laser beam transmission distances or the influence on the accuracy of the elevation detection during the development of the laser receiver, and were not used to conduct systematic tests and regular analyses.

Therefore, in this study, the law of laser beam spot diameter transmission and diffusion is studied by testing. Optimization designed a new type of laser receiver, and a calculation method of elevation deviation of a rotating laser is proposed, through densely arranged photoelectric conversion arrays and 
rotating laser elevation deviation calculation methods, which accurately obtain the geometric center elevation position of the laser beam spot image, and detection accuracy of elevation deviation can be adjusted in multi-level (that could be set to $\pm 3 \mathrm{~mm}, \pm 6 \mathrm{~mm}, \pm 9 \mathrm{~mm}, \pm 12 \mathrm{~mm}$, and $\pm 15 \mathrm{~mm}$ ). Based on the tests and analyses, the change rule of the elevation detection accuracy of the laser receiver on the transmission distance was also evaluated. The laser receiver designed in this article can be shared with agricultural laser graders and concrete levelers to meet the farmland construction requirements and the construction requirements of the concrete industry, which are of a high standard.

\section{Laser Receiver Design}

The structure of the laser receiver is shown in Figure 1. It consists of a photoelectric conversion array, filter and amplifier, shaping and stretching circuits, a microprocessor, and a bus.

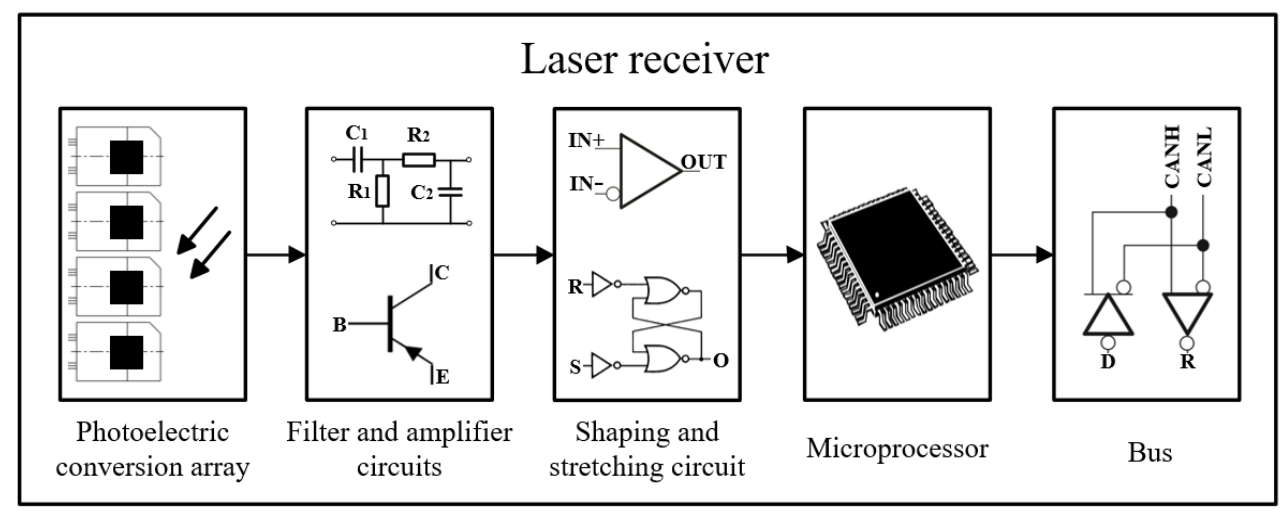

Figure 1. Diagram of laser receiver structure.

\subsection{Photoelectric Conversion Array}

The photoelectric conversion array selected a silicon photodiode (Everlight Electronic, PD638C) as the photodetector (package size of $7.5 \mathrm{~mm} \times 5.5 \mathrm{~mm}$, a photosensitive surface size of $3 \mathrm{~mm} \times 3 \mathrm{~mm}$, response time: $50 \mathrm{~ns}$, and wavelength of peak sensitivity: $940 \mathrm{~nm}$ ). The arrangement of the photoelectric conversion array is shown in Figure 2, whereby 152 silicon photodiodes are arranged in 38 rows and 4 columns, and the interval between the adjacent silicon photodiodes is $0.5 \mathrm{~mm}$. This makes the vertical effective detection distance of the laser receiver to be $225 \mathrm{~mm}$. The angle between the four rows of the silicon photodiodes and the receiver circuit board is $45^{\circ}$ and the angle of each silicon photodiode is $90^{\circ}$, which can realize the laser receiver detect the laser signal from $0^{\circ}$ to $360^{\circ}$. 


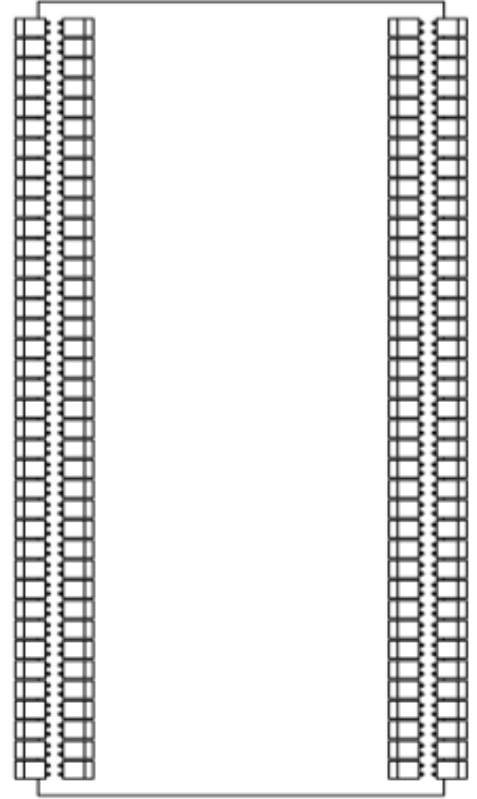

(a)

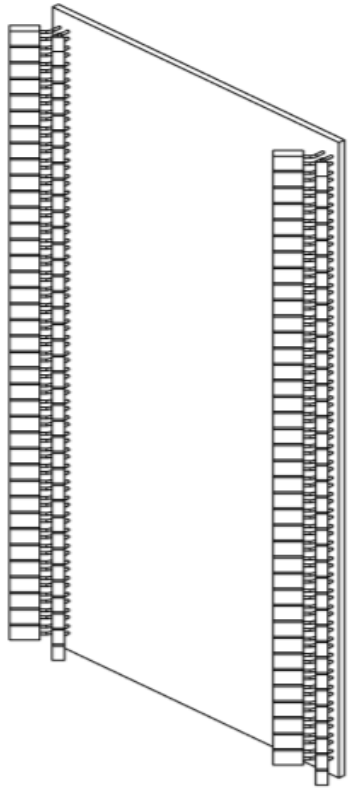

(b)

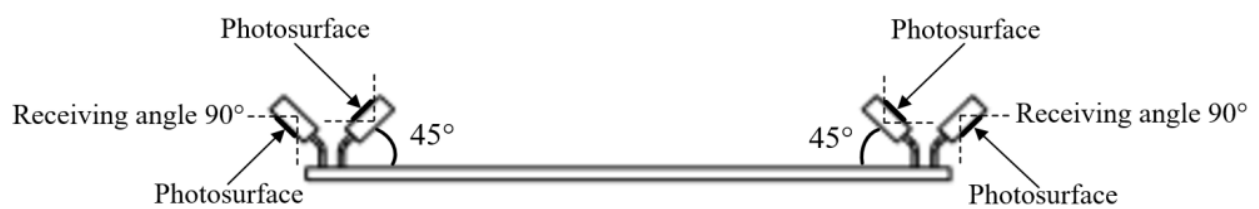

(c)

Figure 2. Schematic of the arrangement of the photoelectric conversion array. (a) Front view, (b) solid view, (c) top view.

\subsection{Filter and Amplifier Circuit}

The photocurrent signal after the photoelectric conversion is weak, and it is accompanied by noise signal interference. Thus, it is necessary to design a filter amplifier circuit with high gain and low noise characteristics [27].

The laser transmitter rotates at a speed of 600 revolutions/min. After the photoelectric conversion, a periodic pulse signal with a frequency of $10 \mathrm{~Hz}$ can be obtained. The calculation of the pulse signal width $\tau$ is shown in Equation (1).

$$
\tau=\frac{1}{10} * \frac{w_{b}}{2 \pi l}
$$

In the equation, $\tau$ is the pulse signal width in $\mu \mathrm{s}, l$ is the laser beam transmission distance in $\mathrm{m}$, and $w_{b}$ is the width of the photosensitive surface of the silicon photodiode in $\mathrm{mm}$.

The center frequency $f_{b}$ of the band-pass filter is shown in Equation (2). As indicated, as the laser beam transmission distance increases, the center frequency of the band-pass filter increases. Therefore, the center frequency of the band-pass filter should be calculated based on the shortest distance between the laser receiver and the laser transmitter, to ensure that within the working range of the laser receiver, the frequency of the pulse signal is concentrated at the center frequency of the band-pass filter.

$$
f_{b}=\frac{w_{b}}{2 \pi}=\frac{1}{2 \tau}=\frac{10 \pi l}{w_{b}}
$$

In the above equation, $f_{b}$ is the center frequency of the band-pass filter. 
After the filtering process, the PNP transistor is selected to form a single-stage, common emitter amplifier circuit, to amplify the millivolt-level voltage signal. The voltage gain calculation is shown in Equation (3).

$$
G u=20 \lg A u=20 \lg (U o / U i)
$$

In the equation, $U_{o}$ is the output voltage of the amplifier circuit in $\mathrm{V}$, and $U i$ is the input voltage of the amplifier circuit in V.

\subsection{Shaping and Stretching Circuit}

To facilitate the microprocessor to process the data, the filtered and amplified signal needs to be shaped and pulse stretched. First, a differential comparator is used to convert the filtered and amplified signal into a transistor-transistor logic (TTL) signal, with a frequency of $10 \mathrm{~Hz}$ and a duty cycle of $1 \%$. Second, a trigger signal with a frequency of $100 \mathrm{~Hz}$ and a duty cycle of $0.008 \%$ is used to trigger the tri-stable R-S latch, to achieve pulse stretching. The principle is shown in Figure 3. When the shaped input signal $S_{n}$ is at a low level and the trigger signal $R_{n}$ is at a high level, the output signal $O_{n}$ is at a high level. When the shaped input signal $S_{n}$ is at any level and the trigger signal $R_{n}$ is at a low level, the output signal $O_{n}$ is at a low level. When the shaped input signal $S_{n}$ is at a high level and the trigger signal $R_{n}$ is at a high level, the output signal $O_{n}$ is in a latched state. The trigger signal $R_{n}$ stretched the duty cycle of the input signal $S_{n} 10$ times, that is, the duty cycle was stretched from $1 \%$ to $10 \%$.

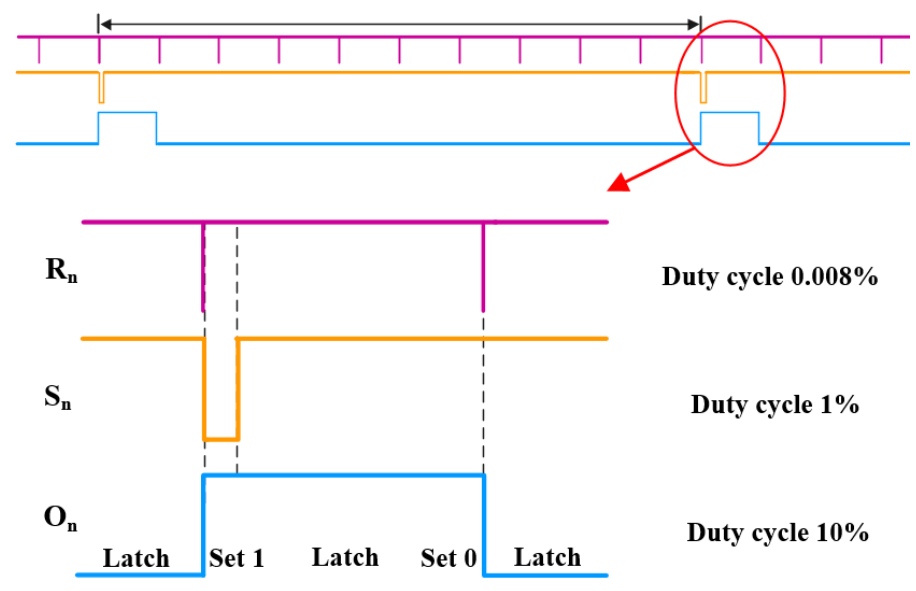

Figure 3. Principle of pulse stretching. (Note: Set 1, high-level state; Set 0, low-level state.).

\section{Transmission and Diffusion of Laser Beam Spot Diameter}

In ideal conditions, the laser beam generated by the laser transmitter through the laser gain medium, pump source, and optical cavity, is a Gaussian beam. The spot gradually diffuses as the transmission distance increases. Accordingly, the diffusion rate first increases and then stabilizes [28]. The transmission and diffusion law of the Gaussian beam spot diameter is expressed by Equation (4).

$$
D=2 r=2 r_{0} \sqrt{1+\left(\frac{\lambda x}{\pi r_{0}^{2}}\right)^{2}}
$$

In the equation, $D$ is the spot diameter in $\mathrm{mm}, r$ is the spot radius in $\mathrm{mm}, x$ is the transmission distance in $\mathrm{m}, r_{0}$ is the initial spot radius in $\mathrm{mm}$, and $\lambda$ is the wavelength in $\mathrm{nm}$.

\subsection{Equipment and Method for Spot Diameter Measurement Test}

The laser beam spot image collection test was performed in a sports field, and the test scheme and main equipment are shown in Figure 4. At the beginning of the $100 \mathrm{~m}$ runway, a laser beam analyser (Spiricon, L11059) was installed on a lifting platform (accuracy $=0.01 \mathrm{~mm}$ ) to fine-tune the 
displacement, and was connected to a laptop (DELL, Inspiron-11) via a universal serial bus (USB) interface. Additionally, a pulsed laser mode was selected to be at $10 \mathrm{~m}, 20 \mathrm{~m}, \ldots$, $90 \mathrm{~m}$, and $100 \mathrm{~m}$ away from the laser transmitter (Topcon, RL-H4C), to collect laser beam spot images. The BeamGage (Ophir-Spiricon, v6.8) software was used to analyze the fitted Gaussian of the beam of the laser beam spot image, and the laser beam spot diameter was calculated at transmission distances in the range of 100-200 m.

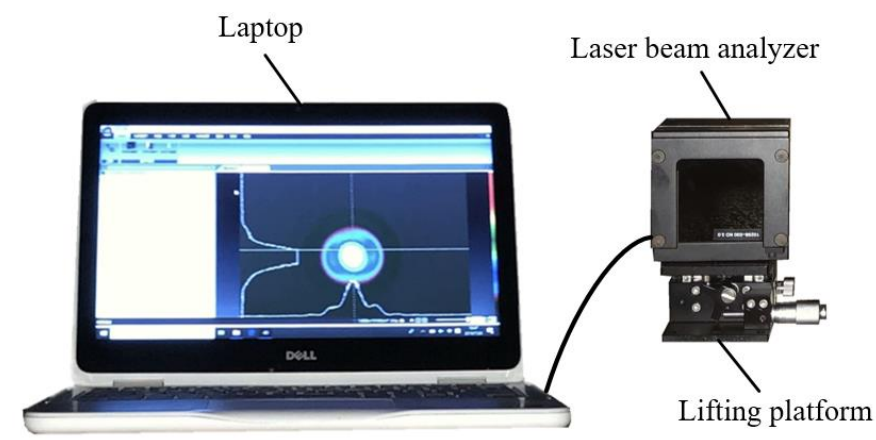

Figure 4. Test equipment of laser beam spot image collection.

The laser beam spot diameter measurement test that can be detected by the laser receiver was carried out at the research base of the South Chinese Agricultural University in Guangzhou. The test scheme and main equipment are shown in Figure 5. As shown, the laser receiver installed on the manual lift contains only one silicon photodiode that can detect the laser signal (other silicon photodiodes are covered by a black film). When the laser beam transmission distance is $10 \mathrm{~m}, 20 \mathrm{~m}, \ldots, 190 \mathrm{~m}$, and $200 \mathrm{~m}$, the elevation position of the laser receiver is adjusted by the manual lift (accuracy $=0.05 \mathrm{~mm}$ ), and the digital grating ruler (accuracy $=5 \mu \mathrm{m}$ ) is used to measure the laser beam spot diameter that can be detected by the laser receiver.

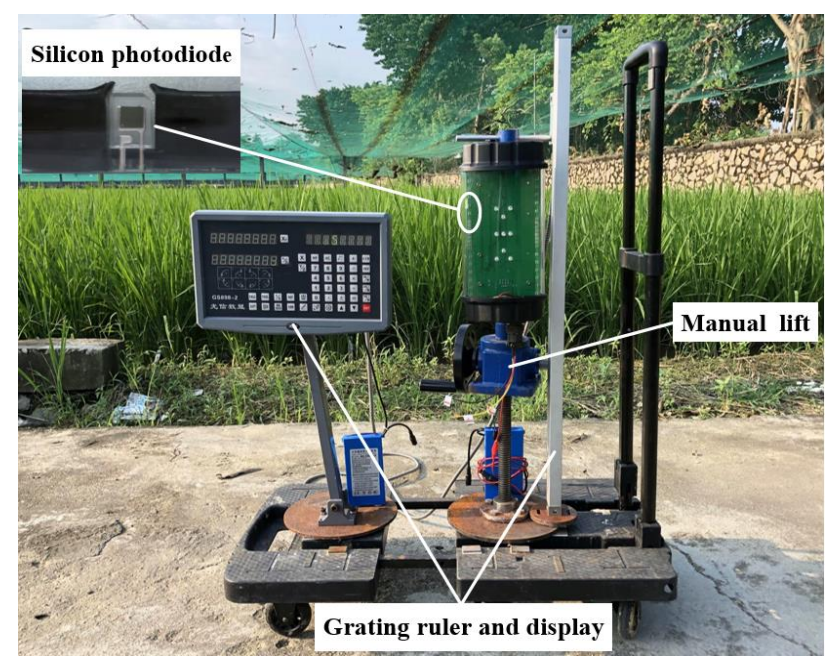

Figure 5. Set-up used for the laser beam spot diameter measurements.

\subsection{Law and Analysis of Spot Diameter Transmission and Diffusion}

The laser beam spot images at the transmission distances of $10 \mathrm{~m}, 30 \mathrm{~m}, 50 \mathrm{~m}, 70 \mathrm{~m}$, and $90 \mathrm{~m}$, are shown in Figure 6. As the transmission distance increases, the spot of the laser beam continues to diffuse and forms a multistage amplified light ring. 

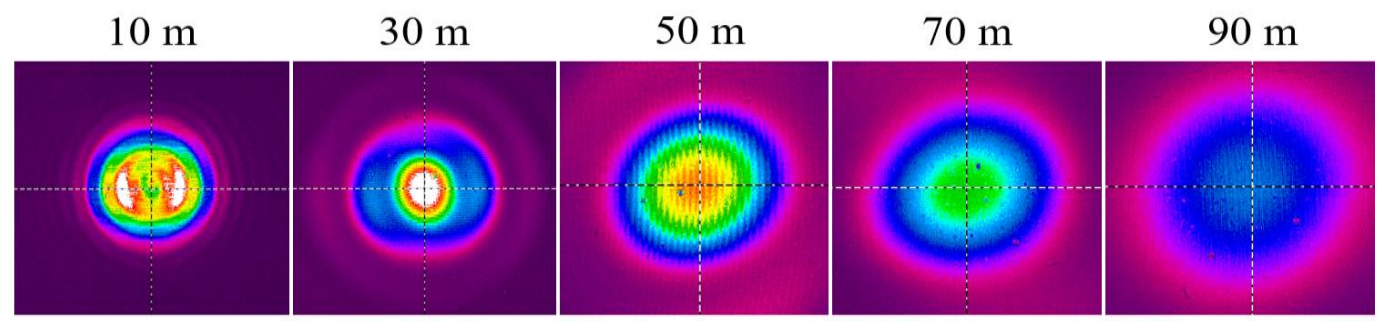

Figure 6. Laser beam spot image.

The comparison of the actual and detectable laser beam spot diameters are shown in Figure 7 for transmission distances in the range of 10-200 $\mathrm{m}$. The transmission and diffusion law of the laser beam spot diameter is consistent with that of the Gaussian beam spot diameter (expressed by Equation (4)), but it is significantly different from the corresponding law of the detected laser beam spot diameter. When the transmission distance is in the range of $10-50 \mathrm{~m}$, the range of the laser beam spot diameter that can be detected is $6.85-8.93 \mathrm{~mm}$. When the transmission distance is in the range of $50-150 \mathrm{~m}$, the fitting equation of the detectable laser beam spot diameter is $Y_{1}=0.1971 X_{1}-1.256\left(R^{2}=0.9985\right)$, and the spot diameter is increased from $8.93 \mathrm{~mm}$ to $28.53 \mathrm{~mm}$. When the transmission distance is greater than $150 \mathrm{~m}$, the laser beam spot diameter gradually becomes smaller, and the fitting equation of the detectable laser beam spot diameter is $Y_{2}=-0.07923 X_{2}+38.91\left(R^{2}=0.9978\right)$.

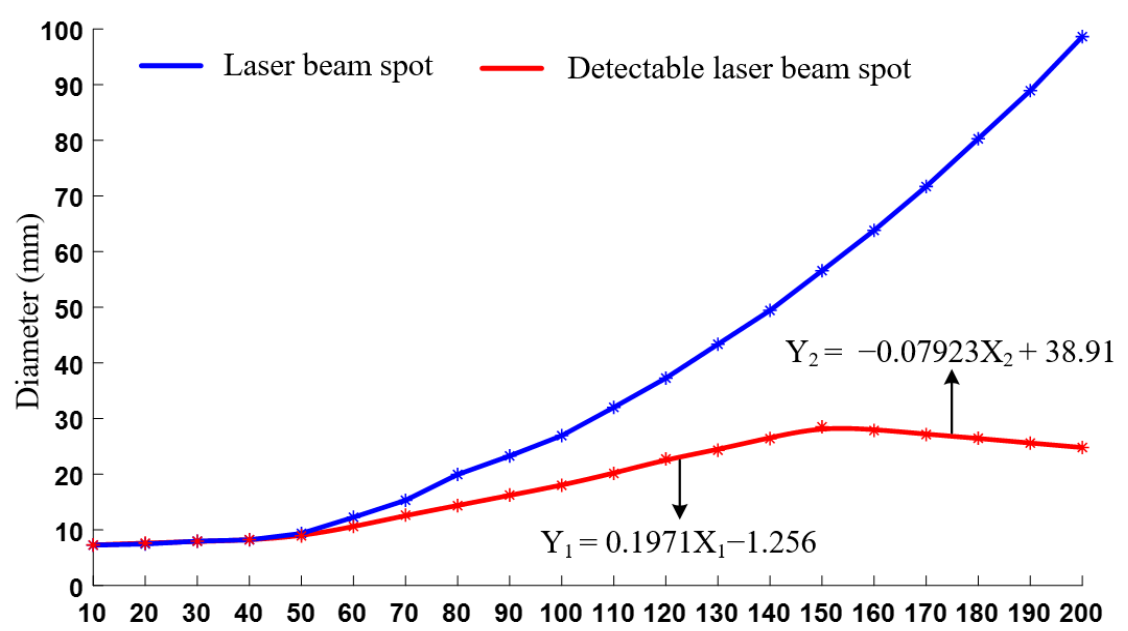

Figure 7. Comparison of results of the laser beam spot diameter and the detectable laser beam spot diameter.

\section{Calculation of Rotating Laser Elevation Deviation}

A schematic of the rotating laser illumination photoelectric conversion array is shown in Figure 8. When the photosensitive surface of a silicon photodiode is illuminated by the rotating laser, the elevation deviation is calculated as the error between the center position of the illuminated silicon photodiode and the zero position of the laser receiver. As the transmission distance increases, the laser beam spot diameter becomes larger, and when the photosensitive surface of multiple silicon photodiodes is illuminated by the rotating laser at the same time, the elevation deviation is calculated as the error between the centers' positions of the illuminated multiple silicon photodiodes and the zero position of the laser receiver. This calculation method can accurately obtain the geometric center elevation position of the laser beam spot image, and it can effectively reduce the calculation error of elevation deviation caused by the laser beam spot diffusion. 


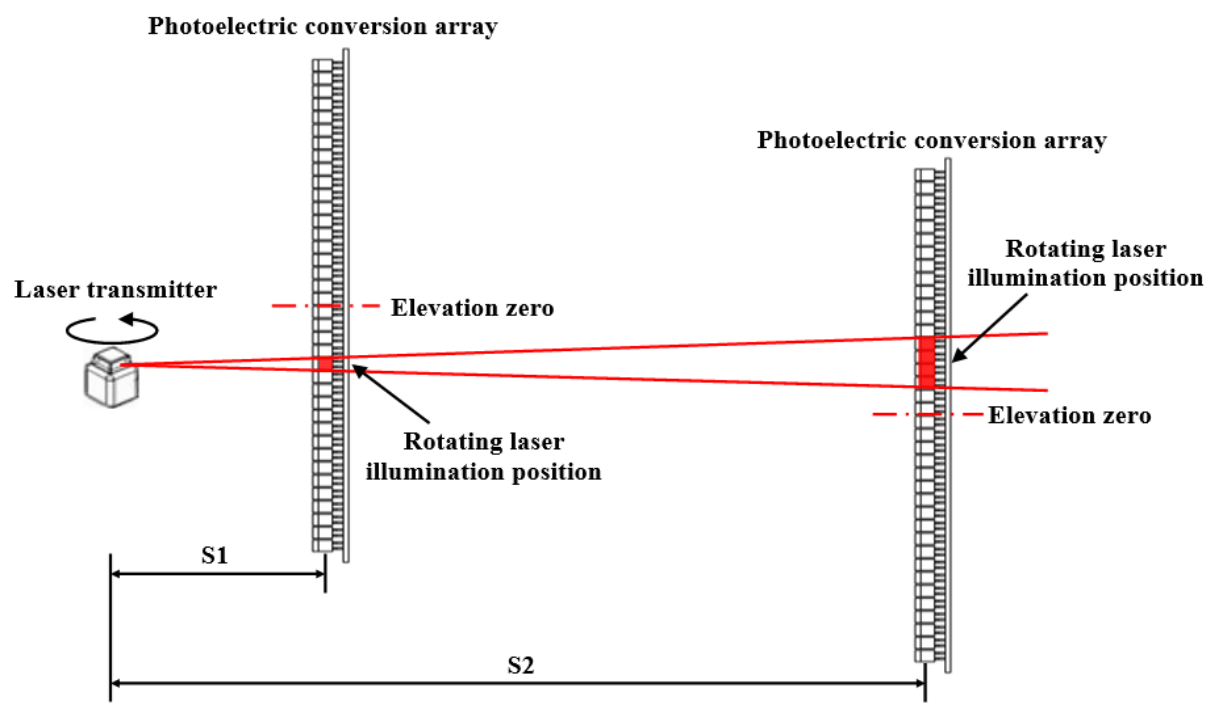

Figure 8. Schematic of rotating laser illumination photoelectric conversion array. (Note: in the schematic, a side view of the photoelectric conversion array is shown. When the transmission distance is S1, a silicon photodiode is illuminated by the rotating laser; when the transmission distance is S2, four silicon photodiodes are illuminated by the rotating laser.).

The longitudinal center of the photoelectric conversion array is defined as the zero position. When the rotating laser is illuminated above the zero position, elevation deviation is defined as a positive number. In all other cases, elevation deviation is defined as a negative number. The calculation of elevation deviation is expressed by Equation (5).

$$
\Delta x= \begin{cases}\frac{(i-j) \times(a+b)}{2} & i \neq 0, j \neq 0 \\ \frac{\left(n_{\max }+n_{\text {min }}-1\right) \times(a+b)}{2} & i \neq 0, j=0 \\ \frac{\left(m_{\max }+m_{\min }+1\right) \times(a+b)}{2} & i=0, j \neq 0\end{cases}
$$

In the above equation, $\Delta x$ is the elevation deviation in $\mathrm{mm}, i$ is the number of silicon photodiodes above the zero position illuminated by the rotating laser, $j$ is the number of silicon photodiodes below the zero position illuminated by the rotating laser, $a$ is the width of the silicon photodiode in $\mathrm{mm}$, $b$ is the distance between two adjacent silicon photodiodes in $\mathrm{mm}, n$ is the code (1-19) of the silicon photodiode above the zero position illuminated by the rotating laser, and $m$ is the code $(-1$ to -19$)$ of the silicon photodiode below the zero position illuminated by the rotating laser.

The width of the silicon photodiode is $a=5.5 \mathrm{~mm}$, and the distance between two adjacent silicon photodiodes is $b=0.5 \mathrm{~mm}$. According to Equation (5), the elevation deviation detection resolution is $\pm 3 \mathrm{~mm}$. By modifying the equation used to calculate the elevation deviation in the algorithm, the accuracy of the elevation deviation detection can be set to $\pm 3 \mathrm{~mm}, \pm 6 \mathrm{~mm}, \pm 9 \mathrm{~mm}$, $\pm 12 \mathrm{~mm}$, and $\pm 15 \mathrm{~mm}$. Therefore, the accuracy can be adjusted at a multiple level to meet different accuracy requirements.

\section{Tests and Analyses}

\subsection{Testing and Analysis of the Laser Receiver Elevation Detection Accuracy}

\subsubsection{Test Materials and Methods}

The test method is shown in Figure 9; the laser transmitter (Topcon, RL-H4C) is mounted on the ground on a tripod. The elevation position of the laser receiver, which can be adjusted by the hand wheel, is mounted on a manual lift (accuracy $=0.05 \mathrm{~mm}$ ). The grating ruler (measurement resolution $=5 \mu \mathrm{m}$ ) is used to measure the elevation deviation. The main parameters of the laser 
receiver are the pulse signal width range from 0.239 to $4.78 \mu$ s and the band-pass filter center frequency of $1050 \mathrm{~Hz}$. The theoretical value of the laser beam spot diameter is the detectable laser beam spot diameter, and the elevation deviation is calculated according to Equation (5). The main parameters are the number of silicon photodiodes illuminated, the code of the silicon photodiodes illuminated; the width of the silicon photodiode is $5.5 \mathrm{~mm}$, and the distance between two adjacent silicon photodiodes is $0.5 \mathrm{~mm}$. Therefore, the elevation deviation detection resolution is $\pm 3 \mathrm{~mm}$. The trolley is used to carry test equipment to adjust the distance from the laser transmitter; the tape measure (range $=50 \mathrm{~m}$, accuracy $=0.01 \mathrm{~m}$ ) is used to calibrate the distance. Moreover, the elevation detection accuracy test was performed every $10 \mathrm{~m}$, so that the laser receiver stopped for the first time at the critical position of the output elevation deviation of $0 \mathrm{~mm}$ and $3 \mathrm{~mm}$, and stopped for the second time at the critical position of the output elevation deviation of $0 \mathrm{~mm}$ and $-3 \mathrm{~mm}$. Accordingly, the elevation deviation measured by the grating ruler and the number of silicon photodiodes illuminated by the rotating laser was observed and recorded.

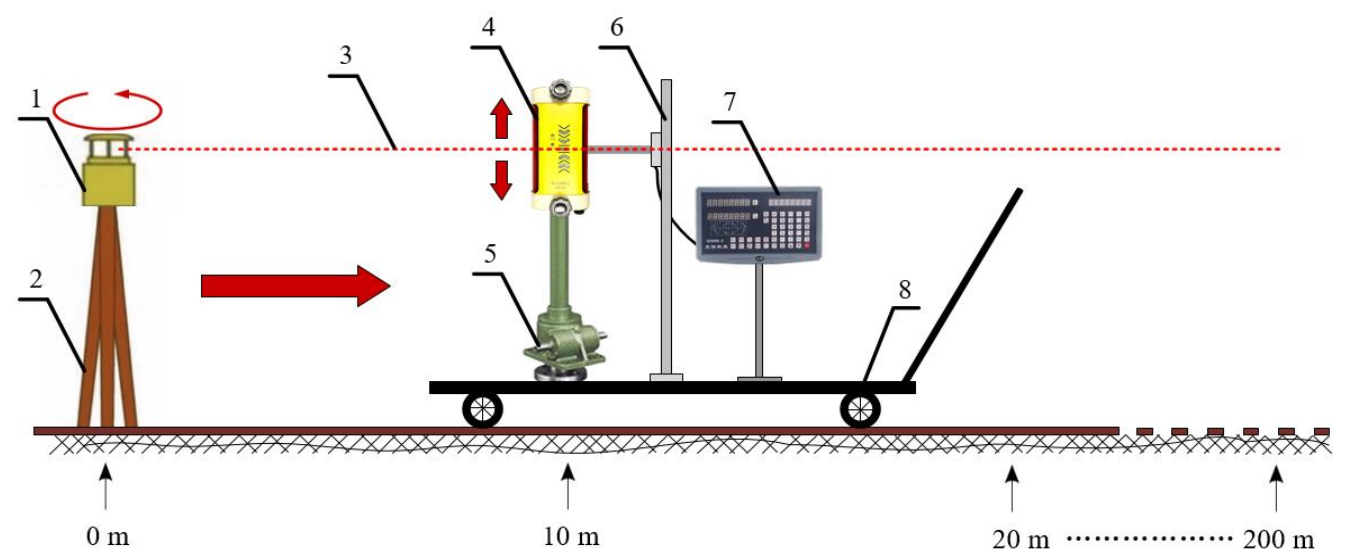

Figure 9. Schematic of testing setup. (1. Laser transmitter, 2. Tripod, 3. Laser reference, 4. Laser receiver, 5. Manual lift, 6. Grating ruler, 7. Data display instrument, and 8. Trolley.).

\subsubsection{Test Data and Analysis}

The data of the number of silicon photodiodes illuminated and elevation detection accuracy absolute error, which calculated theoretically and measured experimentally, are listed in Table 1. When the detectable laser beam spot diameter is in the range of $3 \sim 9 \mathrm{~mm}$, the theoretical value of the number of silicon photodiodes illuminated is 1 or 2; when the detectable laser beam spot diameter is in the range of $9 \sim 15 \mathrm{~mm}$, the theoretical value of the number of silicon photodiodes illuminated is 2 or 3 ; when the detectable laser beam spot diameter is in the range of $15 \sim 21 \mathrm{~mm}$, the theoretical value of the number of silicon photodiodes illuminated is 3 or 4 ; when the detectable laser beam spot diameter is in the range of $21 \sim 27 \mathrm{~mm}$, the theoretical value of the number of silicon photodiodes illuminated is 4 or 5 ; when the detectable laser beam spot diameter is in the range of $27 \sim 33 \mathrm{~mm}$, the theoretical value of the number of silicon photodiodes illuminated is 5 or 6 . The test comparison results show that the theoretical value of the number of silicon photodiodes illuminated by the laser beam spot is consistent with the measured value. When the transmission distance is less than or equal to $90 \mathrm{~m}$, the measured value of absolute error of the elevation detection accuracy of the laser receiver at each test point is less than $3 \mathrm{~mm}$. When the transmission distance is greater than $90 \mathrm{~m}$, the measured value of absolute error pertaining to the elevation detection accuracy is greater than $3 \mathrm{~mm}$, mainly owing to the combined effect of the laser beam spot transmission diffusion law and the laser beam spot drift phenomenon. This is because the elevation deviation detection error increases gradually as the transmission distance increases. 
Table 1. Test results of elevation detection accuracy.

\begin{tabular}{ccccc}
\hline \multirow{2}{*}{$\begin{array}{c}\text { Transmission } \\
\text { Distance }(\mathbf{m}) .\end{array}$} & \multicolumn{2}{c}{$\begin{array}{c}\text { Number of Silicon Photodiodes } \\
\text { Illuminated }\end{array}$} & \multicolumn{2}{c}{ Absolute Error (mm) } \\
\cline { 2 - 5 } & Theoretical Value & Measured Value & Theoretical Value & Measured Value \\
\hline 10 & 1 or 2 & 2 & 3 & 1.605 \\
20 & 1 or 2 & 2 & 3 & 1.59 \\
30 & 1 or 2 & 2 & 3 & 1.435 \\
40 & 1 or 2 & 2 & 3 & 1.675 \\
50 & 1 or 2 & 2 & 3 & 1.82 \\
60 & 2 or 3 & 2 & 3 & 1.975 \\
70 & 2 or 3 & 2 & 3 & 2.43 \\
80 & 2 or 3 & 2 & 3 & 2.785 \\
90 & 3 or 4 & 4 & 3 & 2.91 \\
100 & 3 or 4 & 4 & 3 & 3.295 \\
110 & 3 or 4 & 4 & 3 & 3.455 \\
120 & 4 or 5 & 4 & 3 & 3.635 \\
130 & 4 or 5 & 4 & 3 & 3.83 \\
140 & 4 or 5 & 4 & 3 & 4.045 \\
150 & 5 or 6 & 6 & 3 & 4.12 \\
160 & 5 or 6 & 6 & 3 & 4.245 \\
170 & 5 or 6 & 6 & 3 & 4.42 \\
180 & 4 or 5 & 4 & 3 & 4.3825 \\
190 & 4 or 5 & 4 & 3 & 4.475 \\
200 & 4 or 5 & 4 & 3 & 4.565 \\
\hline
\end{tabular}

\subsection{Farmland-Levelling Test and Analysis}

\subsubsection{Test Purpose and Standard}

It is important to study the instant at which the laser receiver is used in conjunction with the agricultural grader, to ascertain whether the farmland levelling effect meets the high standard farmland construction requirements. According to the GB/T30600-2014 farmland construction standard, the elevation deviation of the field surface should be within $\pm 3 \mathrm{~cm}$ after levelling.

\subsubsection{Test Materials and Methods}

In June 2019, a dry land levelling test was conducted in the Qingyuan City in the Chinese Province of Guangdong, whereby the test field was approximately $60 \mathrm{~m}$ long, $30 \mathrm{~m}$ wide, had an area of approximately $1800 \mathrm{~m}^{2}$, and was sun-cured for more than $24 \mathrm{~h}$ after rotary tillage. The drill and laser grader [29] are shown in Figure 10. The tractor was a Kubota M704KQ, and the laser transmitter was a Topcon RL-H4C. To reduce the elevation adjustment oscillation of the scraper, the accuracy of the laser receiver was set to $\pm 9 \mathrm{~mm}$.

Before the test, the field was measured with a $50 \mathrm{~m}$ tape and was divided into $5 \times 5 \mathrm{~m}$ grids. The grid intersections denote the sampling points (a total of 69). The expected elevation reference point $\mathrm{O}$ is calibrated on the ridge and set to the origin of the coordinate system $(0,0,0)$. A digital level (Topcon, AT-B4) was used to measure the elevation of each sampling point relative to the reference point O. During the test, the laser transmitter (Topcon, RL-H4C) was set up in the ridge, and the drill and laser graders carried out S-type farmland-levelling operations with an average speed of $2.34 \mathrm{~km} / \mathrm{h}$. After the test, the elevation of each sampling point relative to the reference point $\mathrm{O}$ was measured with the use of a digital level. 


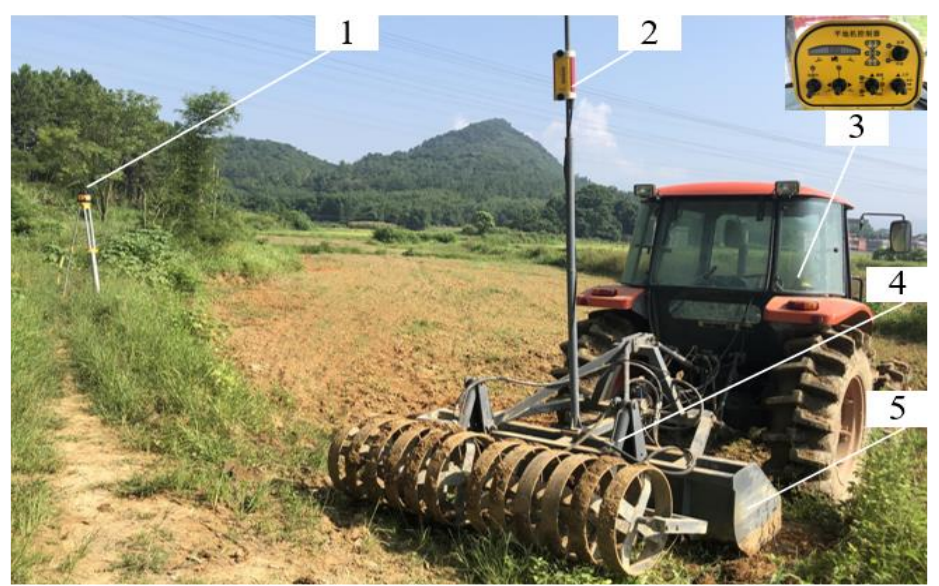

Figure 10. Test site of farm levelling. (1. Laser transmitter, 2. Laser receiver, 3. Controller, 4. Hydraulic system, and 5. Scraper.).

\subsubsection{Test Data and Analysis}

Figure 11a shows a three-dimensional (3D) topographical map before levelling, while Figure 11b shows a 3D topographical map after levelling. As indicated in this figure, the field surface is uneven before levelling, and the flatness of the field surface is significantly improved after levelling.

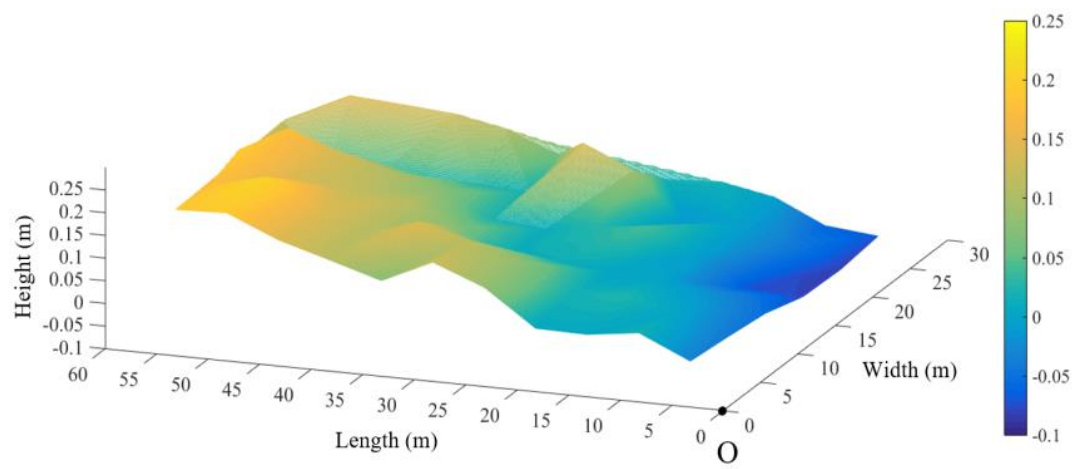

(a)

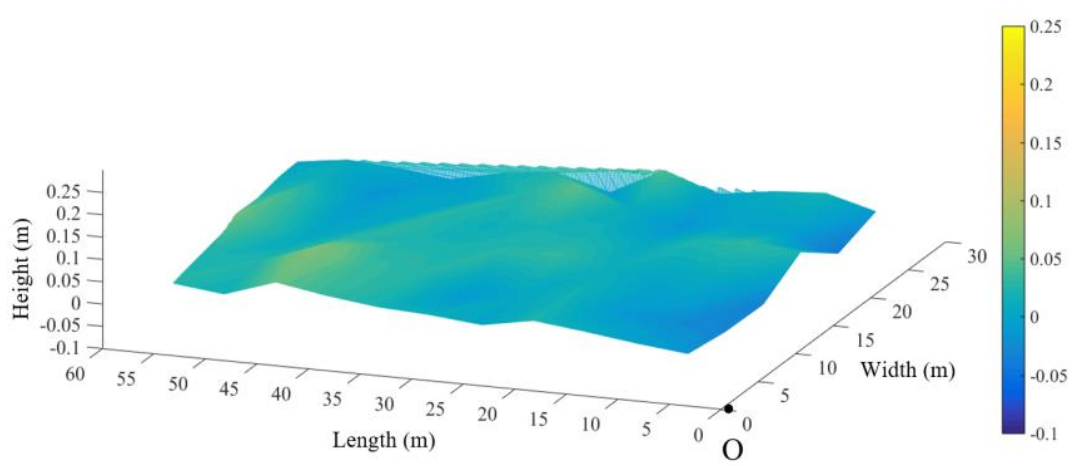

(b)

Figure 11. Three-dimensional (3D) topographical map before and after levelling. (a) Before levelling, (b) After levelling.

As shown in Equation (6) and Equation (7), the test estimates the flatness of the farmland, based on the standard deviation of the elevation $S_{d}$ of the sampling points. It was found that the percentage 
of the absolute error between the sampling point elevation and the expected elevation was $\leq 3 \mathrm{~cm}$. This reflects the characteristics of the farmland elevation error distribution [1].

$$
\begin{aligned}
& S_{d}=\sqrt{\sum_{i=1}^{n}\left(h_{i}-h_{e}\right)^{2} /(n-1)} \\
& P\left(\left|h_{i}-h_{e}\right| \leq 0.03\right)=\frac{m}{n} \times 100 \%
\end{aligned}
$$

In the above two equations, $h_{i}$ denotes the elevation of the sampling point in $\mathrm{cm}, h_{e}$ is the expected elevation in $\mathrm{cm}, n$ is the number of sampling points, $m$ is the number of the absolute error between the sampling point elevation, and the expected elevation is $\leq 3 \mathrm{~cm}$.

The test results are listed in Table 2. After levelling, the maximum elevation error of the field surface decreases from $28.9 \mathrm{~cm}$, before levelling to $11.1 \mathrm{~cm}$, while the standard deviation $S_{d}$ of the field surface decreases from $9.54 \mathrm{~cm}$ before levelling to $2.42 \mathrm{~cm}$ after levelling, and the percentage of the sampling points for absolute errors less than or equal to $3 \mathrm{~cm}$ is $84.06 \%$. The test results show that when the laser receiver is used with the agricultural grader, the flatness of the field surface is significantly improved, and the requirements of farmland construction standards are thus met.

Table 2. Experiment results off arm levelling.

\begin{tabular}{cccc}
\hline Levelling State & $\begin{array}{c}\text { Maximum Elevation } \\
\text { Error }(\mathbf{c m})\end{array}$ & $\begin{array}{c}S_{d} \\
(\mathbf{c m})\end{array}$ & $\begin{array}{c}\boldsymbol{P}\left(\left|h_{i}-\boldsymbol{h}_{\boldsymbol{e}}\right| \leq \mathbf{3}\right) \\
\mathbf{( \% )}\end{array}$ \\
\hline Before levelling & 28.9 & 9.54 & 37.68 \\
After levelling & 11.1 & 2.42 & 84.06 \\
\hline
\end{tabular}

\subsection{Concrete Levelling Test and Analysis}

\subsubsection{Test Purpose and Standard}

The optimal time instant at which the laser receiver should be used in conjunction with the concrete leveler was studied, to ascertain whether the deviation of the elevation adjustment and the effect of the levelling operation met the construction requirements of the concrete industry. According to the concrete paving standards set by the American Concrete Institute (ACI) and the Canadian Standards Association (CSA), during the construction process, the adjustment of the elevation deviation of the system consisted of the laser receiver and the controller. Within a radius of $30 \mathrm{~m}$, this adjustment needed to be less than or equal to $\pm 3 \mathrm{~mm}[30]$.

\subsubsection{Test Materials and Methods}

The laser transmitter (Topcon, RL-H4C) generates a rotating laser signal. The level sensor (Topcon, RE160, accuracy $=0.5 \mathrm{~mm}$ ) is selected for zero position calibration, deviations in elevation adjustment, and for sampling point elevation measurements. Two laser receivers were installed on the left and right masts of the concrete leveler.

The test site is shown in Figure 12. As indicated, the laser transmitter is set at $0 \mathrm{~m}$, and the sand bed is paved within $30 \mathrm{~m}$ with a length of $10 \mathrm{~m}$, width of $2.5 \mathrm{~m}$, and a thickness of $5 \mathrm{~cm}$. Level sensors were used to calibrate the zero position of the laser receiver. The elevation position was adjusted manually by the control system, and the status of the elevation indicator was recorded. Additionally, the value of the elevation deviation was set as the initial elevation deviation for automatic adjustment. Finally, we switched to the automatic adjustment mode, and measured and recorded the elevation deviation of the stopped position after the automatic adjustment. The running speed of the levelling operation was approximately $0.45 \mathrm{~km} / \mathrm{h}$, and 10 sampling points were selected at regular intervals (interspacing of $1 \mathrm{~m}$ ), from the left, middle, and right sides of the sand bed after the levelling (for a 
total of 30 sampling points). We used the level sensor to measure and record the deviation between the elevation of the sampling point and the expected elevation.

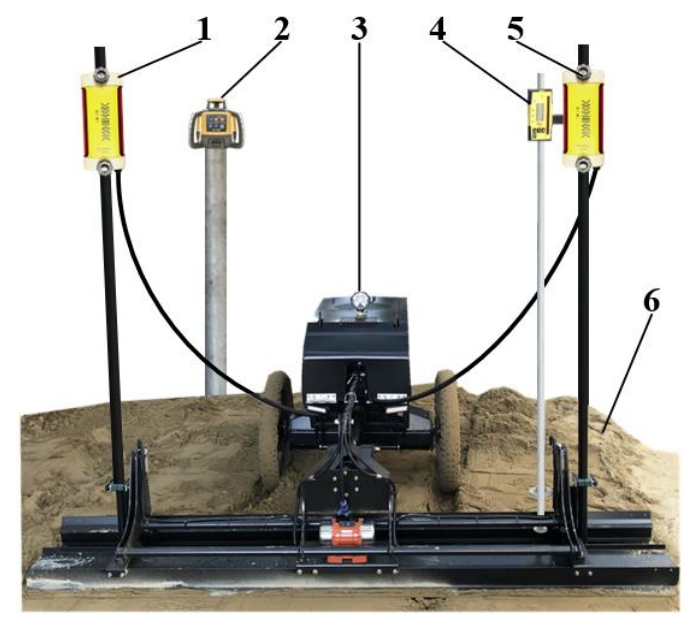

Figure 12. Test site of concrete levelling. (1. Left laser receiver, 2. Laser transmitter, 3. Concrete leveler, 4. Level sensor, 5. Right laser receiver, and 6. Sand bed).

\subsubsection{Test Data and Analysis}

When the initial elevation deviation is in 4 different elevation LED states, the left and right laser receivers perform 10 automatic adjustments. The test data scatter plot is shown in Figure 13. As shown, within a radius of $30 \mathrm{~m}$, the left and right laser receivers are automatically adjusted at different initial elevation deviations, and the elevation deviations are randomly distributed within $\pm 2.5 \mathrm{~mm}$. Accordingly, the deviation of the elevation adjustment is met within a range of $\pm 3 \mathrm{~mm}$, in accordance with the test standard.

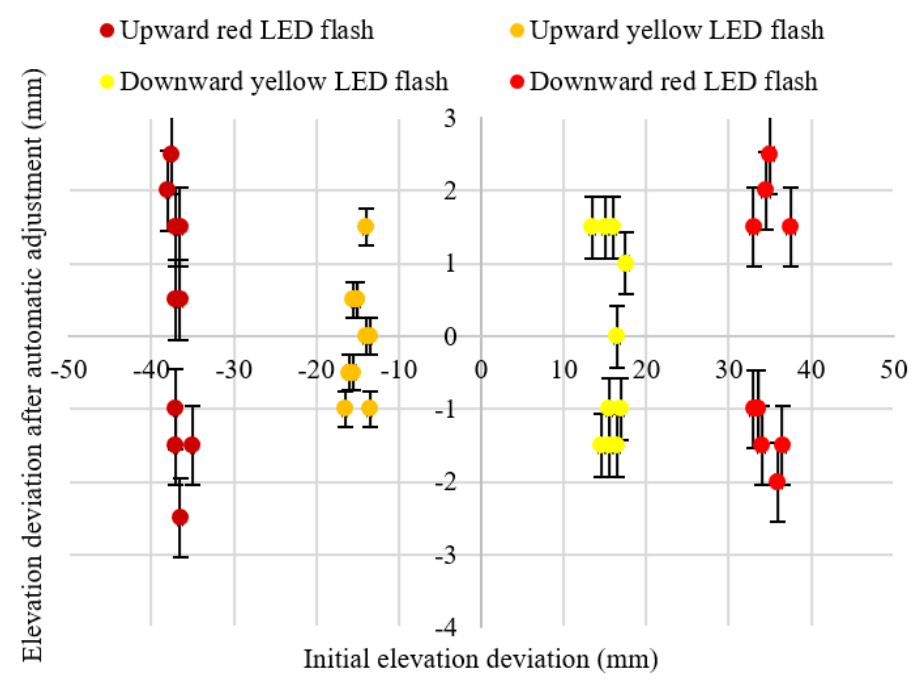

(a)

Figure 13. Cont. 


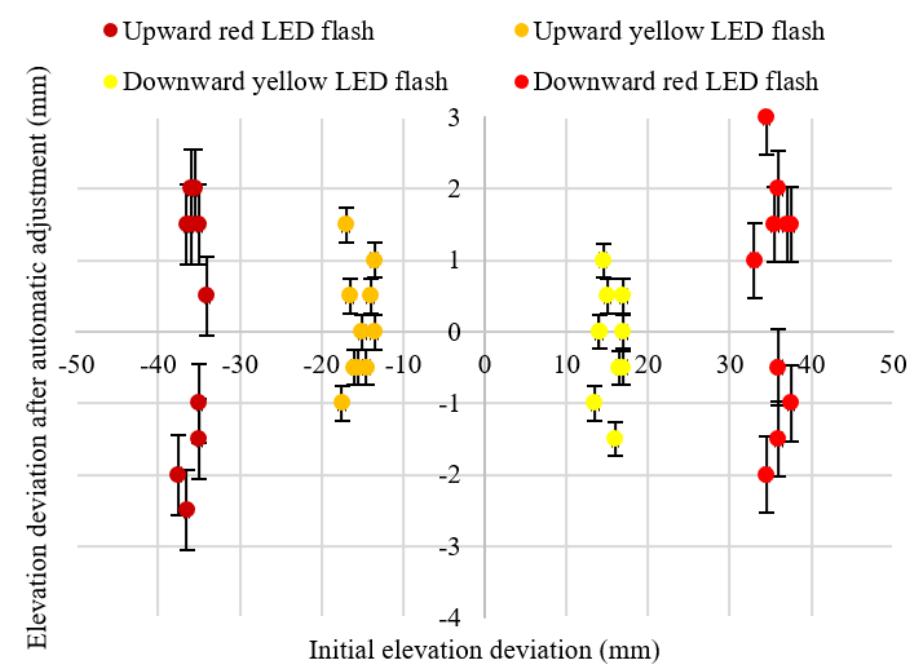

(b)

Figure 13. Test data scatter plot of the deviation of the elevation adjustment. (a) Left laser receiver, (b) Right laser receiver. (Note: The laser receiver had five sets of elevation light-emitting diodes (LED), and four states were used in the test, including the upward red LED flash, upward yellow LED flash, downward yellow LED flash, and downward red LED flash.)

According to the test data, we calculated the standard deviation $S_{d}$ and the percentage of absolute error, which was less than $3 \mathrm{~mm}$ of the elevation adjustments in the cases of the left and right laser receivers. The test results are listed in Table 3 . Within a radius of $30 \mathrm{~m}$, the standard deviation $S_{d}$ of the elevation adjustment of the left laser receiver was $1.389 \mathrm{~mm}$, and the standard deviation $S_{d}$ of the elevation adjustment of the right laser receiver was $1.316 \mathrm{~mm}$. In addition, the percentage of the absolute error which was less than $3 \mathrm{~mm}$ of the elevation adjustment of the two laser receivers was $100 \%$.

Table 3. Elevation adjustment test outcomes.

\begin{tabular}{ccc}
\hline Laser Receiver Position & $\begin{array}{c}S_{d} \\
(\mathbf{m m})\end{array}$ & $\begin{array}{c}\boldsymbol{P}\left(\left|\boldsymbol{h}_{\boldsymbol{i}}-\mathbf{h}_{\mathrm{e}}\right| \leq \mathbf{0 . 0 0 3}\right) \\
\mathbf{( \% )}\end{array}$ \\
\hline Left & 1.389 & 100 \\
Right & 1.316 & 100 \\
\hline
\end{tabular}

According to the test data, we calculated the standard deviation $S_{d}$ and the percentage of the sampling points. The test results are listed in Table 4 . The standard deviation $S_{d}$ is $0.881 \mathrm{~mm}$, and the percentage of the sampling points with elevation absolute errors of $\leq 3 \mathrm{~mm}$ was $100 \%$. Therefore, the laser receiver designed in this study can be used with the concrete leveler to meet the construction standards of the concrete industry.

Table 4. Experimental results of levelling project.

\begin{tabular}{ccc}
\hline Levelling State & $\begin{array}{c}\boldsymbol{S}_{\boldsymbol{d}} \\
(\mathbf{m m})\end{array}$ & $\begin{array}{c}\boldsymbol{P}\left(\left|\boldsymbol{h}_{\boldsymbol{i}}-\mathrm{h}_{\mathrm{e}}\right| \leq \mathbf{0 . 0 0 3 )}\right. \\
\mathbf{( \% )}\end{array}$ \\
\hline After levelling & 0.881 & 100 \\
\hline
\end{tabular}

\section{Discussion and Conclusions}

(1) In this study, the silicon photodiode was used as the photodetector. Based on the study of the laser signal detection technology and processing circuit, regular patterns of the laser beam spot diameter transmission and diffusion, and solution methodology related to the deviation of the rotating 
laser elevation, we optimization designed a multilevel adjustable laser receiver, through densely arranged photoelectric conversion arrays and rotating laser elevation deviation calculation methods, to accurately obtain the geometric center elevation position of the laser beam spot image. Accordingly, the test results of elevation detection accuracy showed that when the laser receiver was within a radius of $90 \mathrm{~m}$, the elevation detection accuracy was within $\pm 3 \mathrm{~mm}$.

(2) When the laser receiver was used with the agricultural grader, the test results of farmland levelling showed that the standard deviation $S_{d}$ of the field surface decreased from $9.54 \mathrm{~cm}$, before levelling to $2.42 \mathrm{~cm}$ after levelling, and the percentage of sampling points with elevation absolute errors of $\leq 3 \mathrm{~cm}$ was $84.06 \%$. These outcomes meet the requirements of the high standard of farmland construction.

(3) When the laser receiver was used with the concrete leveler, the test results of the levelling showed that after levelling, the standard deviation $S_{d}$ of the sand bed surface was $0.881 \mathrm{~mm}$, and the percentage of the sampling points of the absolute error less than or equal to $3 \mathrm{~mm}$ was $100 \%$. These outcomes also met the construction standards of the concrete industry.

(4) As the transmission distance increased, the elevation detection accuracy of the laser receiver decreased, owing to the laser beam spot transmission diffusion and the laser beam drift phenomenon. It is concluded that the solution of the interference of the laser beam drift phenomenon on the detection accuracy of the laser receiver requires additional research.

Author Contributions: S.M., L.H. and Y.Z. wrote the original draft, designed the circuit and board. X.L. and L.H. were responsible for supervising this research and involved in exchanging ideas, reviewing and revising the article draft. R.Z., P.D., J.J., H.H. and G.C. completed the test and data collection were taken the tests and data curation. All authors have read and agreed to the published version of the manuscript.

Funding: This research was funded by the Key-Area Research and Development Program of Guangdong Province (No. 2019B020224001) and the National Key Research and Development Program of China (No. 2017YFD0701105) and the Special Innovation Projects of Education Department of Guangdong Province (No. 2019).

Conflicts of Interest: The authors declare no conflict of interest.

\section{References}

1. Li, Y.; Xu, D.; Li, F.; Du, P.; Li, W. Evaluation of the application effects of laser-controlled precision land-levelling technology on a large scale. Trans. CSAE 2008, 24, 69-73. (In Chinese with English abstract)

2. Abdullayev, I.; Hassan, M.U.; Jumaboev, K.; Hassan, M.M.U. Water saving and economic impacts of land leveling: the case study of cotton production in Tajikistan. Irrig. Drain. Syst. 2007, 21, 251-263. [CrossRef]

3. Larson, N.; Sekhri, S.; Sidhu, R. Adoption of water-saving technology in agriculture: The case of laser levelers. Water Resour. Econ. 2016, 14, 44-64. [CrossRef]

4. Ali, A.; Hussain, I.; Rahut, D.B.; Erenstein, O. Laser-land leveling adoption and its impact on water use, crop yields and household income: Empirical evidence from the rice-wheat system of Pakistan Punjab. Food Policy 2018, 77, 19-32. [CrossRef]

5. Kaur, B.; Singh, S.; Garg, B.R.; Singh, J.M.; Singh, J. Enhancing water productivity through on farm resource conservation technology in Punjab agriculture. Agric. Econ. Res. Rev. 2012, 25, 79-85.

6. Fangmeier, D.D.; Clemmens, A.J.; El-Ansary, M.; Strelkoff, T.S.; Osman, H.E. INFLUENCE OF LAND LEVELING PRECISION ON LEVEL-BASIN ADVANCE AND PERFORMANCE. Trans. ASAE 1999, 42, 1019-1025. [CrossRef]

7. Salassi, M.E. Estimated costs of precision land grading with on-farm labor. J. Farm Managers Rural Appraisers 2001, 29, 26-31.

8. Thakar, S.; Gill, M.S.; Sidhu, H.S.; Sukhpreet, S.; Sidhu, A.S. Effect of laser land leveling on water productivity and yield ofrice-wheat cropping system. Indian J. Ecol. 2009, 36, 95-97.

9. Bai, G.; Du, S.; Yu, J.; Zhang, P. Laser land leveling improve distribution of soil moisture and soil salinity and enhance spring wheat yield. Trans. CSAE 2013, 29, 125-134. (In Chinese with English abstract)

10. Naresh, R.K.; Gupta, R.K.; Kumar, A.; Prakesh, S.; Tomar, S.S.; Singh, A.; Rathi, R.C.; Misra, A.K.; Singh, M. Impact of laser land leveler for enhancing water productivity in Western Uttar Pradesh. Int. J. Agric. Eng. 2011, 2, 133-147. 
11. Hoque, M.; Hannan, M. Performance evaluation of laser guided leveler. Int. J. Agric. Res. Innov. Technol. 2015, 4, 82-86. [CrossRef]

12. Jat, M.; Gathala, M.; Ladha, J.; Saharawat, Y.S.; Jat, A.; Sharma, S.; Gupta, R.; Kumar, V.; Kumar, V. Evaluation of precision land leveling and double zero-till systems in the rice-wheat rotation: Water use, productivity, profitability and soil physical properties. Soil Tillage Res. 2009, 105, 112-121. [CrossRef]

13. Hu, L.; Xu, Y.; He, J. Design and test of tractor-attached laser-controlled rotary scraper land leveller for paddy fields. J. Irrigation Drain. Eng. 2020, 146, 04020002. [CrossRef]

14. Maqsood, L.; Mahmood Khalil, T. A review of direct and indirect implications of laser land leveling as agriculture resource conservation technology in Punjab province of Pakistan. In Proceedings of the 2013 IEEE Global Humanitarian Technology Conference (GHTC), San Jose, CA, USA, 20-23 October 2013; pp. 20-23.

15. $\mathrm{Xu}, \mathrm{D}$.; Li, Y.; Liu, G. Research progress on the application system of laser-controlled precision land leveling technology. Trans. CSAE 2007, 23, 267-272. (In Chinese with English abstract)

16. Zhao, R.; Hu, L.; Luo, X.; Zhou, H.; Du, P.; Tang, L.; He, J.; Mao, T. A novel approach for describing and classifying the bottom layer unevenness of paddy fields. Comput. Electron. Agric. 2019, 162, 552-560. [CrossRef]

17. Hu, L.; Yang, W.; He, J.; Zhou, H.; Zhang, Z.; Luo, X.; Zhao, R.; Tang, L.; Du, P. Roll angle estimation using low cost MEMS sensors for paddy field machine. Comput. Electron. Agric. 2019, 158, 183-188. [CrossRef]

18. Tang, L.; Hu, L.; Zang, Y.; Luo, X.; Zhou, H.; Zhao, R.; He, J. Method and experiment for height measurement of scraper with water surface as benchmark in paddy field. Comput. Electron. Agric. 2018, 152, 198-204. [CrossRef]

19. İrsel, G.; Altinbalik, M.T. Adaptation of tilt adjustment and tracking force automation system on a laser-controlled land leveling machine. Comput. Electron. Agric. 2018, 150, 374-386. [CrossRef]

20. Liu, G.; Lin, J.; Si, Y.; Hou, M.; Mao, E.; Wang, M. Development and experiment on laser controlled leveling system. Trans. Chin. Soc. Agric. Mach. 2006, 37, 71-74. (In Chinese with English abstract)

21. Xie, X.; Liu, G.; Lang, X. Laser receiver used for laser controlled land leveling system. Trans. Chin. Soc. Agric. Mach. 2009, 40, 77-81. (In Chinese with English abstract)

22. Ke, X.; Luo, X. Optimization design of laser receiver amplification circuit of laser leveler for paddy field. Trans. CSAE 2014, 30, 1-7. (In Chinese with English abstract)

23. Trimble Laser Leveling System Specification. Available online: http://www.shtbag.com/productPage/ laserLandLevelingMachine.html (accessed on 16 September 2019).

24. Leica Laser Leveling System Specification. Available online: http://www.leicageosystems.com.cn/leica_ geosystems/productdetail.aspx?tnid=628\&bigcolid=3 (accessed on 16 September 2019).

25. Topcon Precision Agriculture Technology. Available online: https://www.topconpositioning.com/ (accessed on 16 September 2019).

26. LR-8 Line Laser Receiver Specification. Available online: https://www.boschtools.com/us/en/boschtools-ocs/ laser-receivers-38925-c/ (accessed on 16 September 2019).

27. Graeme, J.G. Photodiode Amplifiers op Amp Solutions; Science Press: Beijing, China, 2012.

28. Wu, J.; Yu, Z.; Zhuge, J. Self-calibration method for rotating laser positioning system using interscanning technology and ultrasonic ranging. J. Opt. Soc. Am. A 2016, 33, 544-550. [CrossRef] [PubMed]

29. Hu, L.; Du, P.; Luo, X. Design and experiment on multi-wheel support laser land leveler hanging on tractor. Trans. Chin. Soc. Agric. Mach. 2019, 2019, 15-21. (In Chinese with English abstract)

30. Li, X.; Zhang, Y. Research on large area concrete leveling technology. Constr. Technol. 2014, 43, 318-321. (In Chinese with English abstract)

(C) 2020 by the authors. Licensee MDPI, Basel, Switzerland. This article is an open access article distributed under the terms and conditions of the Creative Commons Attribution (CC BY) license (http://creativecommons.org/licenses/by/4.0/). 